Hobson, A.J. \& Ashby, P. (2012) Reality aftershock and how to avert it: second year teachers' experiences of support for their professional development. Cambridge Journal of Education, 42(2), 177-196.

\title{
Reality aftershock and how to avert it: second year teachers' experiences of support for their professional development
}

\author{
Andrew J. Hobson and Patricia Ashby \\ Department of Teacher Education, Sheffield Hallam University, $U K^{*}$
}

\begin{abstract}
Drawing on analyses of data from a large-scale, mixed method study of new entrants to the teaching profession in England, this article presents new findings on beginner teachers' experiences of postinduction support for their professional development, about which little was previously known. As well as highlighting positive and negative aspects of support provision, it is shown that the recognised phenomenon of 'reality shock' (Gaede, 1978) is not confined to the transition between initial teacher preparation and teachers' first year in post, since some second year teachers experience a new or additional shock associated with the cessation of the induction support introduced, in part, to cushion the impact of that transition. Amongst the potential implications of these findings, it is argued that where they do not already exist, formal mechanisms should be introduced to facilitate the provision of contingent support for beginner teachers' professional development beyond their first year.
\end{abstract}

Keywords: second year teachers; post-induction support; early professional development; reality shock; transition shock; reality aftershock

\section{Introduction}

This article examines beginner teachers' perceptions and experiences of post-induction support for their professional development, and addresses both its strengths and limitations. It is argued that while the introduction of newly qualified teacher (NQT) induction programmes in England has helped to alleviate the reality shock (Gaede, 1978) typically experienced by NQTs, and while most second year teachers are broadly satisfied with the support they experience, for some the cessation of the induction programmes to which they are exposed, which typically last for one school year, serves to induce an additional jolt associated with their new realities of teaching. We have termed this phenomenon 'reality aftershock', and

\footnotetext{
* Now Education Research Centre, University of Brighton, Brighton, UK. Email: a.hobson@brighton.ac.uk
} 
Hobson, A.J. \& Ashby, P. (2012) Reality aftershock and how to avert it: second year teachers' experiences of support for their professional development. Cambridge Journal of Education, 42(2), 177-196.

define it more fully as difficulties experienced by recently qualified teachers in consequence, or partial consequence, of a perceived cessation or sudden reduction in support for their professional development following their completion of new teacher induction programmes. The findings are derived from analyses of data generated for the 'Becoming a Teacher' (BaT) project, a large scale, mixed method longitudinal study of new entrants to the teaching profession in England (Hobson et al., 2009). We begin by outlining the research and policy context, before explaining the methods employed and subsequently presenting and discussing our findings.

\section{Context: reality shock, new teacher induction and the post-induction knowledge gap}

For at least 30 years, research has recognised a critical phase in the development of beginner teachers from student or trainee into fully-fledged professional, where many have been found to experience reality shock, transition shock (Corcoran, 1981) or what Huberman (1989) calls 'painful beginnings', associated in particular with coming to terms with the harsh realities of a full or relatively full timetable, and with pupil indiscipline (Veenman, 1984; Wideen, MayerSmith, \& Moon, 1998). Stokking, Leenders, De Jong, \& Van Tartwijk (2003) argue that this phenomenon can 'be neutralised to a fairly large extent by making the transition from training to the profession a gradual one' (pp.345-346), and in recent years a number of initiatives have been introduced, in different educational systems, which do appear to make for a more comfortable and gradual transition from trainee to qualified teacher. In England we have witnessed three key policy changes in this area:

(1) an increase in the amount of time student teachers must spend in school during their initial teacher preparation (ITP), where they are mentored by an established teacher;

(2) the introduction of a Career Entry and Development Profile (CEDP), designed to ensure that new teachers' development needs, identified at the end of ITP, are followed up during their first year in teaching and beyond; and

(3) the introduction of a statutory induction programme, which requires schools to support NQTs through the provision of an induction tutor (or mentor) and a reduction in their teaching timetable (Teaching and Higher Education Act, 1998), ${ }^{1}$ whilst also providing for their competence to teach to be assessed against national Standards.

In most cases the induction process in England lasts for one school year, but it may take longer, notably where NQTs work part-time, cannot secure a teaching contract of sufficient 
Hobson, A.J. \& Ashby, P. (2012) Reality aftershock and how to avert it: second year teachers' experiences of support for their professional development. Cambridge Journal of Education, 42(2), 177-196.

duration, or are unable to demonstrate that they have met the requisite Standards within what is often termed 'the induction year'. Broadly comparable arrangements for the induction of NQTs exist in many other systems (McKenzie \& Santiago, 2005), though in a minority, such as New Zealand, the induction period spans two years rather than one. However, with a few notable exceptions, such as the Northern Irish system (Department of Education Northern Ireland (DENI), 2010), the end of induction usually marks the end of statutory support for new entrants to the profession. In 2001 the (then) Department for Education and Skills in England explored its possible extension by introducing a pilot Early Professional Development programme, through which funds were made available to enable 12 selected Local Education Authorities (LEAs) to explore ways of supporting the professional development of second and third year teachers. Most LEA programmes included as key elements both mentoring and the involvement of individual teachers in decisions about how the funding would be used to address their professional development needs. However, despite a positive evaluation (Moor et al., 2005) the pilot was discontinued for reasons that were not made public.

It should be recognised that the introduction of formal support mechanisms for beginning teachers has taken place within a broader context increasingly characterised by performativity and surveillance (Ball, 2003), which have been found to entail the formation of 'anxiety provoking environments' (Lumby, 2009, p. 361) inimical to notions of support and professional development (Mahony, Menter, \& Hextall, 2004). However, research studies suggest that while not all NQTs in England actually receive their statutory induction entitlements, and though the quality of school-based support is variable and the use of the CEDP patchy, in general the reforms outlined above have reduced beginner teachers' experience of reality shock and have enhanced their professional development (Hagger, Mutton, \& Burn, 2010; Soares, Lock, \& Foster, 2008; Totterdell, Heilbronn, Bubb, \& Jones, 2002). Such findings were largely supported by earlier analysis of data generated for the BaT research, which suggested that while first year teachers frequently experienced a daunting combination of 'delightful highs and distressing lows' (Bullough, 2009, p. 34), for most the provision of induction support had done much to facilitate a more comfortable or less painful transition from ITP than that experienced by their predecessors in earlier decades (Hobson et al., 2007; Homer, Malderez, Hobson, \& Tracey, 2008). 
Hobson, A.J. \& Ashby, P. (2012) Reality aftershock and how to avert it: second year teachers' experiences of support for their professional development. Cambridge Journal of Education, 42(2), 177-196.

While studies of the first year of teaching are commonplace, to date few have focused explicitly on the years immediately following, a period known to be crucial for retention (Goddard, O’Brien, \& Goddard, 2006; Smith \& Ingersoll, 2004), and it has been argued that more research is needed in this area (Luft, 2007; Wilson, Hall, Davidson, \& Lewin, 2006). Given this gap in the literature, it is unclear to what extent beginner teachers continue to receive effective support for their professional development beyond the first year, or how they experience the cessation of induction support. We have reported elsewhere (Hobson, 2009; Hobson et al., 2009) that BaT survey respondents' ratings of the support they received declined throughout their first four years in post, with the most marked (and statistically significant) decrease occurring between the first and second years, and that beginner teachers' perceptions of the support they received were a major factor shaping their experiences of becoming and being a teacher, influencing their enjoyment of teaching and their perceived effectiveness, as well as their retention in the profession. In view of these various considerations, including the dearth of research on beginner teachers post-induction, we considered that second year teachers' experiences of support for their professional development merited further investigation, and in this article we report findings resulting from a re-analysis of BaT data pertaining to this question.

We should note at this stage that following the conduct of our new analyses, and while this article was in the final stages of preparation, we discovered that we were not alone in seeking to address gaps in the evidence base on beginner teachers, encountering two newly published articles in this area, each reporting relatively small-scale longitudinal studies. The first (Burn, Mutton, \& Hagger, 2010) reports findings from another English study and focuses on 'the interplay between teachers' dispositions and their working environment' (p.655). The second (Fenwick \& Weir, 2010) discusses beginning geography teachers' experiences of induction and early professional learning in Scotland. We make reference to parallel findings between these studies and our own in the final section of this article.

\section{Methodology}

The BaT research was conducted within a hermeneutic-phenomenological framework, whose prime concern is to attempt to understand human experience from the perspective of the individual actor (Bleicher, 1980; Schutz, 1967). Hence, the research as a whole focussed on beginner teachers' accounts of their experiences, while the specific focus of this article is 
Hobson, A.J. \& Ashby, P. (2012) Reality aftershock and how to avert it: second year teachers' experiences of support for their professional development. Cambridge Journal of Education, 42(2), 177-196.

post-induction second year teachers' perspectives on the support they experienced. We do not seek to claim that focusing solely on beginner teachers' perceptions can tell us everything we need to know about post-induction support for professional development, and we acknowledge that different actors associated with the teachers in our sample might provide different 'truths' relating to the support provided. Nonetheless, to the extent that they provide an accurate representation of their own truths, our participants' accounts of the support they experienced are of fundamental importance because - as suggested earlier - they are central to many other aspects of their experience of becoming and being a teacher. Furthermore, beginner teachers' perspectives should be taken seriously since it is beneficial for those who provide opportunities for early professional development (EPD), as it is for teachers of any kind, to possess an appreciation of how their learners view, interpret and understand their experience (von Glaserfeld, 1996).

Beginning teachers participating in the BaT research had graduated from a range of schooland university-administered ITP programmes, and included both primary and secondary school teachers. The methods of data generation employed included:

(1) an annual survey of a national sample of beginner teachers, taking place over a six year period (2003-2009) spanning the final or only year of respondents' initial teacher preparation and the end of their fourth year in post; ${ }^{2}$

(2) annual in-depth, face-to-face interviews with a selected cohort of survey respondents; ${ }^{3}$ and

(3) part-structured email exchanges ('ejournals') in which the same cohort of participants who took part in the face-to-face interviews were asked via a half-termly email to recount their recent experiences of teaching and professional development. ${ }^{4}$

A more detailed account of the methods of data generation, sampling and data analysis employed for the BaT study in general, and of the limitations of the research, is provided elsewhere (Hobson et al., 2009). The specific datasets analysed for the production of this article comprised:

- survey data generated from 2446 teachers one year after completion of their ITP, in which our chief interest related to the perceptions of their support needs for their second year in teaching reported by those 2258 NQTs who indicated that they were remaining in teaching; 
Hobson, A.J. \& Ashby, P. (2012) Reality aftershock and how to avert it: second year teachers' experiences of support for their professional development. Cambridge Journal of Education, 42(2), 177-196.

- survey data generated from 1973 of the same cohort of teachers two years after completion of their ITP, with a focus on the experiences of support reported by those 1470 teachers who both completed their NQT induction at the end of their first year and continued working as (second year) teachers;

- interview data generated from 73 participants at the end of their first year in post and 64 of the same teachers at the end of their second year, with greater emphasis on the latter; and

- ejournal data generated from 45 participants during their second year in teaching.

The survey and interviews were carried out concurrently at or near the end of participating teachers' first and second years in post, respectively. The questions asked on each occasion were partly informed by the analyses of data generated by the previous year's survey and interviews, and partly by responses to the ejournals conducted at regular intervals during the school year.

The original analyses of the same datasets were conducted in a relatively tight time frame for the primary purpose of reporting to the research sponsors, and focussed on a broad range of issues relating to first and second year teachers, including their employment status, roles and responsibilities, their perceptions of their effectiveness and strengths as teachers, and their ratings of the quality of their work based relationships. The findings of those analyses are reported in Hobson et al. (2007), Tracey et al. (2008) and Hobson et al. (2009, Chapters 5-6).

Partly informed (as suggested above) by the outcomes of the earlier analyses, the re-analysis of BaT data reported in this article focussed more specifically and in much greater depth on teachers' perceptions of support for their professional development in their second year of teaching, including how they experienced the cessation of induction support. 'Quantitative' and 'qualitative' data were analysed simultaneously and in iterative fashion using a number of methods. ${ }^{5}$ Survey data were analysed, via SPSS software, using a variety of statistical techniques including chi-square and t-tests, using the standard probability or $p$-value of 0.05 to indicate statistical significance (Field 2000). Qualitative (interview and ejournal) data were subject to what Braun and Clarke (2006) term a data-driven thematic analysis, relating to second year teachers' experiences of support for their professional development. During the qualitative analysis process, inter-coder reliability checks were carried out on selected issues 
Hobson, A.J. \& Ashby, P. (2012) Reality aftershock and how to avert it: second year teachers' experiences of support for their professional development. Cambridge Journal of Education, 42(2), 177-196.

in an attempt to confirm or increase confidence in findings emerging from our analysis of interview and ejournal data. Most notably, having identified the apparent existence of what we term 'reality aftershock' (RAS) in some participants' accounts of their experience, and having operationalised the concept as stated in the Introduction to this article, each of the current authors independently re-analysed all qualitative data relating to those (41) participants who had completed their NQT Induction by the end of their first year in post and whose Induction had not spanned the summer vacation. ${ }^{6}$ Each participant was assigned to one of three categories to signify that they had experienced RAS, they had not experienced RAS, or that the available evidence was inconclusive. The results of this exercise, together with those of the broader quantitative and qualitative analyses, are presented below.

\section{Findings}

Before discussing what post-induction second year teachers told us of the support they received and their opportunities for professional development, we first outline their expectations a year earlier of what their support needs for the forthcoming year would be.

\section{Second year teachers' support needs}

Towards the end of their first year in post, survey respondents planning to remain in teaching were asked, via an open-ended question, what support they felt they would need over the coming year. Table 1 shows that participants identified both needs and potential sources of support, and that, amongst a wide range of responses, the most common related to the provision of a mentor, with 21 per cent of respondents giving this answer. Further analysis reveals that while those who (at the time of the survey) had not successfully completed or been recommended to pass their NQT induction were more likely to state that they would need mentor support ( 25 per cent of this group gave such a response), as many as 20 per cent of those who had already completed (or been recommended to pass) their induction nevertheless indicated without specific prompting that they would need a mentor in their second year in post. $^{7}$ 
Hobson, A.J. \& Ashby, P. (2012) Reality aftershock and how to avert it: second year teachers' experiences of support for their professional development. Cambridge Journal of Education, 42(2), 177-196.

Table 1. Respondents' perceptions of their support needs for their second year in teaching

\begin{tabular}{|c|c|c|}
\hline Provision of a mentor & $\begin{array}{c}\text { Number of } \\
\text { respondents } \\
466\end{array}$ & $\begin{array}{l}\text { Percentage of } \\
\text { respondents } \dagger \\
21\end{array}$ \\
\hline General support from school & 257 & 11 \\
\hline Advice/guidance about further academic study or research & 221 & 10 \\
\hline Being observed in lessons & 152 & 7 \\
\hline Being kept up-to-date with new developments in teaching & 131 & 6 \\
\hline Careers advice/guidance & 126 & 6 \\
\hline Additional training/professional development opportunities & 126 & 6 \\
\hline Provision of a Learning Support/Teaching/Classroom Assistant & 90 & 4 \\
\hline Reduced teaching timetable & 88 & 4 \\
\hline Support with subject coordination & 74 & 3 \\
\hline Observing the lessons of others & 71 & 3 \\
\hline Being assessed & 70 & 3 \\
\hline Help with lesson planning & 63 & 3 \\
\hline Continued contact with NQT peer group & 58 & 3 \\
\hline Critical friend/buddy & 53 & 2 \\
\hline Support in dealing with children with challenging behaviour & 53 & 2 \\
\hline Reduced volume of work/overall workload & 35 & 2 \\
\hline Time for planning preparation and assessment (PPA) & 23 & 1 \\
\hline Regular feedback on teaching & 19 & 1 \\
\hline Regular teaching of the same class(es) & 18 & 1 \\
\hline Contact with people I trained with & 17 & 1 \\
\hline None & 76 & 3 \\
\hline Don’t know & 291 & 13 \\
\hline Number of cases* & 2258 & \\
\hline
\end{tabular}

*Includes all respondents who were teaching or planning to teach, and who planned to be teaching at the start of the following school year.

$\dagger$ Percentages do not sum to 100 as this was an open-ended question and respondents could give more than one response.

More generally, our analyses of participants' survey, interview and ejournal responses suggest that while a number of NQTs felt ready to undertake their second year in teaching with minimal support (not least the three per cent of survey respondents in Table 1 who answered 'none'), many were not ready for the various forms of assistance provided in their first year to be completely or immediately withdrawn. Some participants hoped and expected that their mentor would 'still be there for them' in their second year, while for others the uncertainty about whether they would be able to access such support was a cause for concern: 
Hobson, A.J. \& Ashby, P. (2012) Reality aftershock and how to avert it: second year teachers' experiences of support for their professional development. Cambridge Journal of Education, 42(2), 177-196.

I do have this fear that everybody will suddenly [say] 'right you're no longer an NQT, so you're going to get no help, no nothing.'

We now proceed to examine second year teachers' accounts of the support they actually received. We focus on those who had completed their NQT induction by the end of their first year in post (the majority of participants) since our data suggest that where the induction period runs into a second school year those teachers' experiences differ from the norm, and that the various reasons for which some second year teachers are still undertaking induction may also impact on their experience of support for their professional development. In the interests of brevity we sometimes refer to post-induction second year teachers as RQTs (recently qualified teachers).

\section{Post-induction support for early career development: the positives}

The majority of RQTs appeared satisfied with the support they received during their second year in post: over three-quarters (76 per cent) of survey respondents indicated that this had been 'good' (38 per cent) or 'very good' (38 per cent), with a relatively small seven per cent stating that support had been 'poor' ( 6 per cent) or 'very poor' ( 1 per cent), and 16 per cent neutral or unable to generalise. Amongst a range of factors which post-induction second year teachers considered supportive of their professional development, the support of school-based colleagues was highly prominent. In their responses to an open-ended survey question asking who or what had aided their development as a teacher during their second year in teaching, colleagues in general were mentioned by just under half ( 49 per cent) of respondents, while specific categories of colleagues, including heads of department, peers, head teachers and line managers, were each referred to by between nine and fourteen per cent of RQTs (see Table 2).

The face-to-face interview and ejournal data shed more light on these findings. Here, participants who discussed factors promoting their professional development tended to make reference to supportive school cultures characterised by one or more of the following four features. First, some RQTs (between a third and a half of interviewees) indicated that their development was supported through collaboration and teamwork - specifically the sharing of resources, co-planning and team teaching: 
Hobson, A.J. \& Ashby, P. (2012) Reality aftershock and how to avert it: second year teachers' experiences of support for their professional development. Cambridge Journal of Education, 42(2), 177-196.

This department is just incredible; you never feel that you're being a nuisance. They come to you and see what you need, past papers, example materials... Everyone works together... that door is never shut because we're in and out all the time.

Table 2. Post-Induction second year teachers' perceptions of factors enhancing their development

\begin{tabular}{lcc}
\hline Colleagues at school/college & $\begin{array}{c}\text { Number of } \\
\text { respondents } \\
\text { Head of department }\end{array}$ & $\begin{array}{c}\text { Percentage of } \\
\text { respondents }\end{array}$ \\
Contact with peers & 198 & 48 \\
Head teacher/principal & 151 & 14 \\
Additional training or CPD & 139 & 10 \\
Line manager & 139 & 10 \\
Mentor & 136 & 9 \\
Teaching assistants/support staff & 115 & 8 \\
Learning from experience & 65 & 4 \\
Nothing & 58 & 4 \\
Don't know & 42 & 3 \\
Number of cases & 22 & 2 \\
\hline
\end{tabular}

*Includes all respondents who had completed their Induction at the end of their first year of teaching and worked as a teacher during their second year.

$\dagger$ Percentages do not sum to 100 as this was an open-ended question and respondents could give more than one response.

Secondly, some participants said they had benefited from specific training programmes or formal opportunities for CPD. Table 2 shows that 10 per cent of survey respondents volunteered that such opportunities had enhanced their development as teachers, while in interviews and ejournals RQTs stressed the value of CPD which was explicitly related to pupil learning and had identifiable applications in their teaching:

$[\mathrm{S}]$ omething ... which has inspired me is [CPD on] barriers to learning. If you can identify the barriers to learning that kids have, and remove them... then it's just like opening the gate and letting them through. 
Hobson, A.J. \& Ashby, P. (2012) Reality aftershock and how to avert it: second year teachers' experiences of support for their professional development. Cambridge Journal of Education, 42(2), 177-196.

Thirdly, Table 2 reveals that while a relatively low eight per cent of respondents identified mentors as enhancing their development as teachers, this represents almost a quarter (24 per cent) of the 34 per cent of post-induction second year teachers who indicated that they had a (formal or informal) mentor (see Table 3). RQTs who had a mentor were also statistically significantly more likely than those without one to give higher ratings of the support they received: 50 per cent of those with a mentor rated the support they received as very good, compared with 35 per cent of those without (chi-square, $p<0.001$ ).

Table 3. At your current school, do you have a mentor?

\begin{tabular}{lcc}
\hline & $\begin{array}{c}\text { Number of } \\
\text { respondents }\end{array}$ & $\begin{array}{c}\text { Percentage of } \\
\text { respondents }\end{array}$ \\
Yes & 483 & 34 \\
No & 916 & 65 \\
Don't know & 7 & 1 \\
Number of cases $*$ & 1406 &
\end{tabular}

*Includes all respondents who had completed a formal Induction programme at the end of their first year of teaching and held a permanent or fixed-term teaching post during their second year.

Finally, a minority of interview and ejournal participants indicated that the provision of noncontact time was highly valuable in supporting their professional development. Specifically, the (minimum) 10 per cent off-timetable entitlement for full-time teachers provided under the 'Planning, Preparation and Assessment' (PPA) initiative (Department for Children, Schools and Families, 2008) was said to have facilitated opportunities for collaborative activities, as well as helping RQTs to achieve a better work-life balance.

In general, participants who experienced effective support for their professional development were able to access both 'instruction-related' and 'psychological' or 'therapeutic' forms of assistance (Gold, 1996), as and when they needed it. The former encompassed support for RQTs' subject matter (content) knowledge, general pedagogical knowledge, and pedagogical content knowledge (Shulman, 1986). Regarding the latter, RQTs clearly also valued colleagues and systems that had regard for their psycho-social and emotional needs, and gave them confidence through recognition, encouragement and trust.

I have [had] lots of support ... with planning, organisation, targets and also just emotionally! All staff at the school are extremely helpful, from caretaker to head 
Hobson, A.J. \& Ashby, P. (2012) Reality aftershock and how to avert it: second year teachers' experiences of support for their professional development. Cambridge Journal of Education, 42(2), 177-196.

teacher ... I feel very lucky to be at a supportive school. I feel I can ask for help, whatever it is that I need.

\section{Limitations of post-induction support for professional development}

Although the evidence presented above suggests that many post-induction second year teachers experienced effective support for their professional development, not all BaT participants could paint such a positive picture and our data expose various limitations in support provision. In general, it is clear that some RQTs did not experience supportive school cultures or, more specifically, have access to the kinds of collaborative working enjoyed by participants cited earlier. Indeed, a number saw their professional development as impeded by social and/or physical isolation, which prevented them from accessing either 'instructionrelated' or 'psychological' support ${ }^{8}$ :

I'm away from the rest of my department ... I haven't been able to benefit from just discussing issues and talking about different types of lessons and getting advice and picking up ideas that way... That has been a real issue.

In addition, Table 3 shows that around two-thirds of post-induction second year teachers did not have access to a mentor, and this includes 58 per cent of those who had explicitly stated at the end of the previous year that they would need one. ${ }^{9}$ That said, not all RQTs who did have mentors appreciated the support they provided. Mentors who were unsympathetic, unapproachable or too busy to help, for example, were valued less highly:

[I]f you ask to see him less than a week ahead you struggle. So you just try and ... work through [any problems].

Some participants complained that the support available to them post-induction was predominantly reactive rather than proactive, sometimes tantamount to fire-fighting, while others reported that issues relating to pupil discipline were exacerbated where senior management failed to give visible backing to behavioural policies, or by the existence of a school culture in which acknowledging difficulty was not the done thing: 
Hobson, A.J. \& Ashby, P. (2012) Reality aftershock and how to avert it: second year teachers' experiences of support for their professional development. Cambridge Journal of Education, 42(2), 177-196.

I am having real hassles with this one girl... [The attitude here is that] you can't have any failings at all, which is a shame ... It's like 'Well, you are a professional now.' You can't say 'I am not very good at this.'

For some RQTs, the awareness of an unsatisfied desire to improve or for help in specific areas was demoralising, while training which was expected or promised but which failed to materialise could result in frustration and even bitterness:

Yeah I can teach, I'm confident, but that doesn't mean I still don't want to learn. They say 'you're doing fine, you'll cope' ... but if someone else isn't doing well 'let's give them more support.' Yeah, I understand that, it's fair enough but what about us? We still ... want to be better at what we're doing...

I was disappointed with the [literacy] results the children had ...and at that point they said 'We should get you some in-house training ... or ... you could do a specific course' ...I was disappointed that didn't materialise.

Finally, some participants complained that they were only allowed access to CPD opportunities seen as relevant to the school's agenda, while others bemoaned the fact that much of their PPA time was unprotected and frequently disrupted:

If there's somewhere they want you to go, you go, but if it's somewhere you want to go, then no.

I get free periods in school but they can be taken up for cover [substituting for absent colleagues]... You just hope your colleagues are there, because if not, you've got to cover them.

Together these various findings may explain why (as Table 4 shows) almost a quarter of RQTs did not rate the support they received as 'good' or 'very good', and why there was a statistically significant decline in respondents' ratings of the support they received between their first and second years in post (paired sample t-test: $t=6.93, p<0.001$ ). We explore these issues further below. 
Hobson, A.J. \& Ashby, P. (2012) Reality aftershock and how to avert it: second year teachers' experiences of support for their professional development. Cambridge Journal of Education, 42(2), 177-196.

Table 4. Teachers' ratings of the support received in their first and second years in post

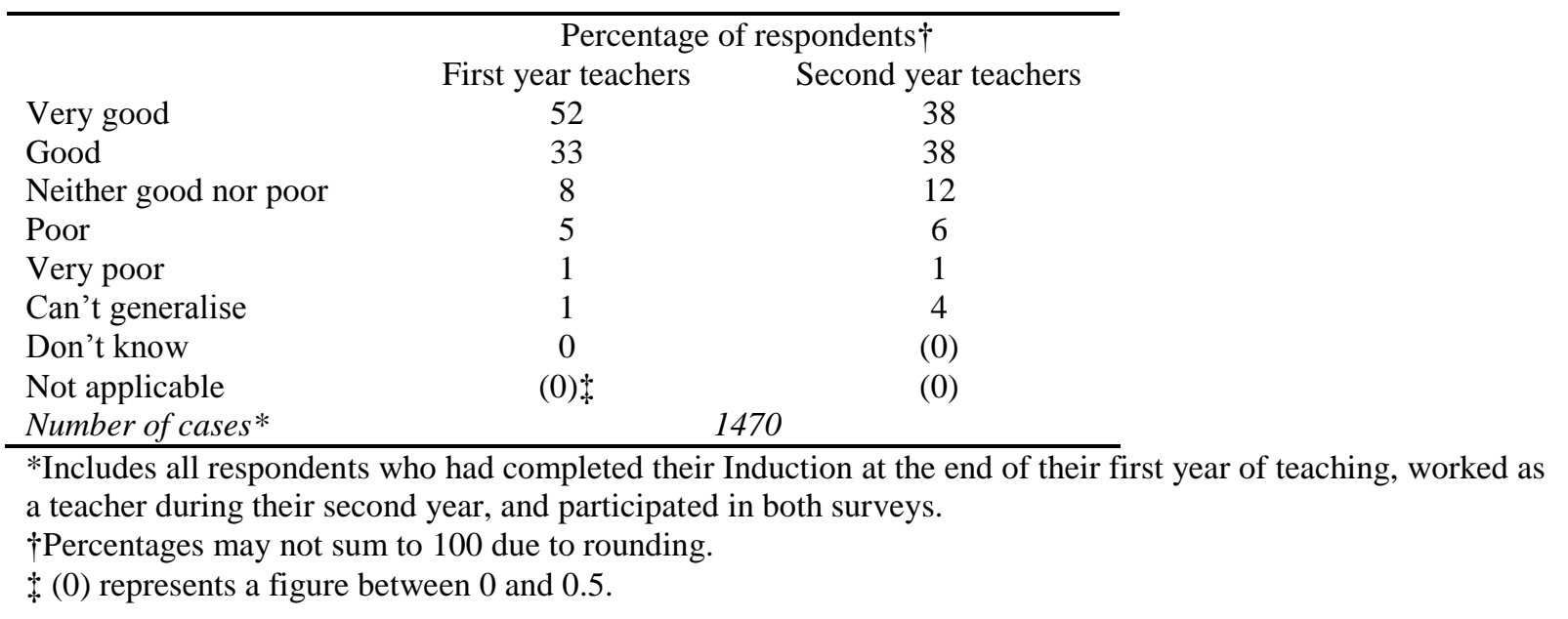

\section{Reality aftershock}

As suggested earlier, our analyses of interview and ejournal data revealed that while there was wide variation in the amount and nature of support provided to post-induction second year teachers, many felt they no longer needed the kinds of support that they had received as NQTs:

I like [my colleagues]... they are approachable but they're not totally on your back all the time... If I've got a problem then I'd like to go and see somebody which we seem to have here...

However, it is clear that many second year teachers (including some of those quoted in the previous section) were not ready for a sudden cessation of induction-related support, and for some the fears of 'no help, no nothing' of the NQT cited earlier were realised:

[T] his school was so good in the NQT year with the training and there was so much there for you [but] it stopped abruptly; there was no sort of follow-on.

I think from PGCE to NQT there is that bridging... From NQT to fully qualified teacher there isn't. 
Hobson, A.J. \& Ashby, P. (2012) Reality aftershock and how to avert it: second year teachers' experiences of support for their professional development. Cambridge Journal of Education, 42(2), 177-196.

One participant conveys an unnerving feeling of being completely cut off from previous sources of support:

...because you are now a qualified teacher, the support that you would have got ordinarily pretty much drops away. Like a booster rocket on a shuttle, that's the way it feels!

Our data thus suggest that some post-induction second year teachers experience a secondary form of reality shock, an additional and (for some) unexpected jolt relating to their new realities as fully qualified and responsible yet relatively unsupported or unprotected teachers. We refer to this phenomenon as reality aftershock, akin to the secondary quake (or series of tremors) that is often experienced following a large earthquake in the same geographical region. Whilst of a lesser magnitude than the original tremor (the transition from student teacher to NQT), an aftershock can nevertheless be damaging and can expose previously unrecognised weaknesses. One RQT, for example, who in her confident and well-supported NQT year 'always knew who to ask' reported feeling vulnerable and 'scared' when faced with what seemed absolute responsibility:

[Y]ou go from always being looked at... to being by yourself and being very accountable very quickly. And that scared me at the time ... that actually this is a class that if I screw up I have got to fix it... I think that change between your NQT [induction] to your second year, where you get quite a lot heaped on extra at once [and] you are suddenly going to take more responsibility ... I think is almost the harder bit...

Worse still, without the awareness of a supportive school culture it becomes more difficult to seek help. As another RQT explained in telling contrast to those whose colleagues were 'approachable', 'You feel guilty if you ask somebody for their opinion'.

As explained in the Methodology section above, an inter-coder reliability exercise was carried out by the present authors in an attempt to uncover the potential prevalence of RAS amongst post-induction second year teacher participants. Of the 64 participants interviewed two years after completing their ITP, 41 were included in this analysis, with the others excluded either because they had not completed their induction before the beginning of their second year in 
Hobson, A.J. \& Ashby, P. (2012) Reality aftershock and how to avert it: second year teachers' experiences of support for their professional development. Cambridge Journal of Education, 42(2), 177-196.

post or because their first full year in teaching (and therefore their NQT induction period) had spanned the summer vacation. ${ }^{10}$ Reality aftershock was operationalised as 'difficulties experienced by RQTs in consequence, or partial consequence, of a perceived cessation or sudden reduction in support for their professional development following their completion of induction', and each participant was to be assigned to one of three categories, signifying that they experienced RAS, they did not experience RAS, or the available evidence was inconclusive. The initial outcome of the coding exercise was agreement in 34 of the 41 cases (an agreement rate of 83 per cent). Following discussion of cases in which we initially disagreed, we reached agreement on all cases and concluded that nine participants (22 per cent) had suffered from RAS, 28 (68 per cent) had not, and four (10 per cent) were unclassifiable.

While the nature of our data does not allow us to estimate the proportion of post-induction second year teachers in the larger survey sample who experienced the phenomenon, we nonetheless consider the potential threat of RAS to be a serious issue, not just in terms of RQTs' well-being but also because of its potential impact on teacher retention. Analysis of our survey data reveal, for instance, that second year teachers who rated the support they received less highly were statistically more likely to leave the profession: 13 per cent of respondents who did not rate the support received in their second year as 'very good' stated that they had left teaching by the end of (what would have been) their fourth year in the profession ${ }^{11}$, compared with a relatively low five per cent of those who reported 'very good' support (chi-square: $p<0.001$ ). The point is strengthened by the following comment from one participant judged to have experienced RAS, who indicated that she would have left teaching had her domestic situation allowed it:

I have to bring in an income at the moment ... If I forgot about that I would walk out tomorrow... [I]fyou've got the support you can manage any school, any class, any area. Without that support it is very hard ... you need support from your mentors, support from your colleagues or whoever else is doing it. You need someone to turn to...

The relatively unsupported second year experience of another participant convinced her not that she should leave the profession but that she should give up her current post in favour of 
Hobson, A.J. \& Ashby, P. (2012) Reality aftershock and how to avert it: second year teachers' experiences of support for their professional development. Cambridge Journal of Education, 42(2), 177-196.

supply teaching, which she hoped would be less demanding, less stressful and less damaging to her family life and personal relationships:

[T] hat's what confuses me: what is the support I'm meant to get or not get? ... After the induction year you just get on with it... Sometimes you worry so much that it kind of makes you moody and aggressive... I really don't want to be in a place where it affects my home life because that's so important to me...

\section{Conclusions and implications: means of strengthening support and averting RAS}

The findings presented in the previous section support earlier studies highlighting the positive impact that supportive school cultures, collaboration and mentoring can have on teachers' early professional development, and - in common with recent findings from the 'Developing Expertise of Beginning Teachers' project (Burn et al., 2010) - confirm the relevance and applicability of such studies to post-induction second year teachers. We have also shown that while the majority of post-induction second year teachers in our sample appeared satisfied with the support provided for their professional development, some did not enjoy the kinds of support they had hoped for, or the supportive school cultures experienced by many of their peers, and we have proposed the term reality aftershock to refer to the negative impact of what some perceived as an abrupt cessation of effective or appropriate support following the completion of their NQT induction. While we would not wish to claim that RAS is as serious or as widespread as the well-established concept of reality shock previously associated with the transition from student teacher to NQT, there is a sense in which the introduction of statutory induction, which appears to have been successful in reducing the severity of reality shock for many (though not eliminating it altogether), may have done so through creating for NQTs something of a modified or even illusory reality in which they no longer have to deal with a full or 'normal' teaching timetable, in which many do not have full pastoral responsibilities, and in which, as some of our participants suggested, the onus is not necessarily on them. Following completion of induction, the genuine reality of a fully qualified teacher takes effect, and many are not prepared for the experience. Though we would urge further exploration of the prevalence of RAS in different educational systems, we note that the findings presented above find some support amongst those reported by both Burn et al. (2010), who refer to a 'sense of professional isolation' (p. 641) experienced by some second year teachers in England following the withdrawal of induction support, and Fenwick 
Hobson, A.J. \& Ashby, P. (2012) Reality aftershock and how to avert it: second year teachers' experiences of support for their professional development. Cambridge Journal of Education, 42(2), 177-196.

and Weir (2010), who report that that some beginner teachers in Scotland experienced 'disrupted and disjointed early professional development' (p. 501), 'missed having a formal mentor' and wanted 'more formal support post-induction' (p. 512).

In considering possible implications of our findings for policy and practice, we would give our backing to calls for exerted efforts to foster school cultures which provide an environment of inclusion and mutual support (Eraut, 2007; Johnson, 2004) and genuine opportunities for collaboration (Cordingley, Bell, Evans, \& Firth, 2005; Meirink, Imants, Meijer, \& Verloop, 2010), to bring beginner teachers into direct contact with the experience and 'professional craft knowledge' of skilled colleagues (Hagger \& McIntyre, 2006), to ensure that EPD provision is flexible and personalised, reflecting beginner teachers' specific needs (Barton, 2004), and to protect non-contact time for RQTs. It also follows from the findings presented above, and from the phenomenon of RAS in particular, that beginning teachers should be encouraged to take greater responsibility for their own learning (Kwakman, 2003; Moor et al., 2005). Alongside efforts to encourage collaboration with colleagues, one key objective of ITP and induction might thus be to seek to empower beginner teachers to move gradually towards autonomy: to encourage them to cope with progressively less assistance while still proactively seeking help when it is needed. Indeed many ITP providers and induction supporters undoubtedly already hold such aspirations for their charges, though to some extent the realization of these is likely to be hampered by the current Standards and assessment mechanisms to which beginner teachers are subject, which can discourage RQTs from being autonomous and proactive, especially in environments where they feel isolated and 'at the bottom of the pecking order' (Hobson, 2009).

Given that some beginner teachers continue to require a range of instructional and/or emotional support after the completion of their first year in post, given the potentially damaging effects of RAS on their well-being, and given evidence suggesting that those who receive effective support and EPD are more likely to derive satisfaction from teaching, have a higher sense of efficacy and remain in the profession (Barton, 2004; Hoy \& Spero, 2005; Johnson 2004), we also urge policy-makers and head teachers (in England at least, to which our data relate) to consider extending contingent support for EPD to teachers' second year in post or beyond. ${ }^{12}$ This might be done either through extending the induction period or by introducing formal mechanisms for post-induction EPD support. Extended induction has been 
Hobson, A.J. \& Ashby, P. (2012) Reality aftershock and how to avert it: second year teachers' experiences of support for their professional development. Cambridge Journal of Education, 42(2), 177-196.

adopted in New Zealand, where 'provisionally registered teachers' (PRTs), supported by an assigned mentor teacher and a reduced timetable, have two years to meet the criteria for full registration (New Zealand Teachers Council, 2011). Post-induction support has been made mandatory in Northern Ireland, where second and third year teachers who have successfully completed their induction are required to take part in an EPD programme designed to develop, expand and consolidate their capability as reflective practitioners (DENI, 2010). Taking into account the positive impact on many beginner teachers of successfully completing their induction and being recognised as fully qualified professionals (Hobson et al., 2007), plus the fact that some RQTs are highly capable and need little more support than far more experienced teachers, we consider the second of these options to be more appropriate, at least in England at this time.

We conclude by drawing attention to some possible components of post-induction support for beginner teachers' professional development that have potential to avert RAS and its detrimental effects. The first is school-based mentoring, currently more prominent internationally in programmes of ITP and induction, but a key element of the pilot EPD programme in England, discussed earlier (Moor et al., 2005), and the major component of the Northern Irish EPD programme, where beginner teachers are supported by 'teacher-tutors' in their schools. ${ }^{13}$ Mentoring by colleagues in their schools was reported as beneficial by many (though not all) of the RQTs in the present study who experienced it. Furthermore, while the full potential of mentoring is sometimes difficult to realise in ITP and NQT induction (or probation), notably because of tensions between the mentor's roles as both supporter and assessor/gatekeeper to the profession (Abell, Dillon, Hopkins, McInerney, \& O’Brien, 1995; Williams \& Prestage, 2002), post-induction the relationship may have greater potential to flourish untrammelled by such considerations, at least where mentors are not involved in an RQT's performance management. Arguably such potential cannot be realized in the existing Northern Irish EPD programme, however, since 'teacher tutors' are required to observe and formally assess the beginner teachers they support.

Yet even if mentors of RQTs are freed from formal assessment duties, attempts to foster effective mentoring, like more general attempts to foster cultures of mutual support in schools, will tend to be constrained by what Ball (2003) refers to as 'the terrors of performativity'. Such terrors comprise the 'myriad of judgments, measures, comparisons and 
Hobson, A.J. \& Ashby, P. (2012) Reality aftershock and how to avert it: second year teachers' experiences of support for their professional development. Cambridge Journal of Education, 42(2), 177-196.

targets' to which teachers and other public sector professionals (in England and many other parts of the world) are subject, which can cause them to become gripped by insecurity and guilt, 'unsure whether [they] are doing enough, doing the right thing, doing as much as others, or as well as others' (Ball, 2003: p.220). Performativity can encourage the formation or exacerbate the existence of school cultures in which, as one of the BaT participants cited earlier put it, 'you can't have any failings... you can't say "I am not very good at this.", It thus discourages teachers from making such disclosures to, and seeking the support of, the very people who might have been best able to help them deal with their perceived failings. Moreover, as suggested by some of the findings presented earlier, RQTs are amongst those most likely to feel insecure. As a second year teacher recently interviewed for a different study put it:

'You don't want to leave yourself open do you? Never leave yourself open to [someone] thinking I'm stupid... You always try to protect yourself a bit.' (Hobson, McIntyre, Ashby, Hayward, Stevens \& Malderez, 2012, p. x)

The consequence is that beginner teachers experiencing problems in macro- (system-based) and micro- (school-based) cultures imbued with performativity are potentially damned if they disclose to colleagues, but also damned if they don't, since without disclosure they may be unable to access the support they need. While the long-term goal must be to change the culture(s), in the short- to medium-term there exists a case for providing RQTs (and perhaps beginner teachers more generally) with opportunities to access a form of support external to the school, from supporters who have no role in the formal assessment of their capability. Two recent approaches to the provision of such support may be particularly apposite and worthy of consideration.

The first is to facilitate continued contact between beginner teachers and their ITP provider. A recent example of this approach was the University of Cambridge Early Professional Development programme. Here beginner teachers of secondary science, who had graduated from the University's Postgraduate Certificate of Education (PGCE) programme, were offered extended contact with their PGCE provider into their second or third year of teaching, in the form of occasional development days at the university led by their ex-tutor, and involvement in a support network comprising their peers and more experienced teachers from 
Hobson, A.J. \& Ashby, P. (2012) Reality aftershock and how to avert it: second year teachers' experiences of support for their professional development. Cambridge Journal of Education, 42(2), 177-196.

the University's partner schools. ${ }^{\mathbf{1 4}}$ The evaluation of the programme found that it helped to compensate for some of the limitations of existing induction and EPD provision, and to provide greater continuity and coherence between ITP and EPD (McIntyre, Hobson, \& Mitchell, 2009). Amongst other benefits participants reported a positive impact on their classroom teaching, increased confidence and reduced stress.

An alternative approach to supporting RQTs is through the allocation of regional, non-schoolbased mentors, such as those deployed in the pilot Physics Enhancement Programme (PEP) and Science Additional Specialism Programme (SASP) in England (Shepherd, 2008). ${ }^{15}$ Recent research into the nature and effectiveness of what we refer to as 'external mentoring' suggests that the teachers who were supported derived considerable benefits, including improved subject content and subject pedagogical knowledge, increased confidence and enjoyment of teaching, and reduced anxiety and stress (Hobson et al., 2012; Holland, Hudson, Cripps, Barley, \& Wolstenholme, 2010).

While all three programmes outlined above were introduced (and funded) to help address specific issues relating to the teaching of secondary science in England, not least the chronic shortage of chemistry and, especially, physics specialists in schools (Moor et al., 2006; Shepherd, 2008), there is no significant reason to attribute their success to their focus on these subjects, and they clearly have possible applicability to other contexts. We would thus urge further consideration of the potential of these and other models for supporting RQTs and averting RAS. The approaches discussed above would not come without their challenges: for example, in some school cultures it might be frowned upon if such teachers were seen to be seeking external support. They would also have considerable cost implications. Yet so too do the immediate and long-term effects of reality aftershock. We have already drawn attention to its possible link to early-career teacher attrition; in addition to the cost of wastage, though, there is a potential, and more insidious, impairment to teacher efficacy. If lack of support and an over-judgmental approach discourage novice teachers from seeking help or deter them from experimenting, their professional development may well be stunted, with a long-term loss to the educational system. In the same way that a sound Early Years foundation is increasingly recognised as important for children's later education, so an education culture sensitive and responsive to the differing needs of new and recent entrants to the teaching profession is likely to reap dividends in their future work in schools. 
Hobson, A.J. \& Ashby, P. (2012) Reality aftershock and how to avert it: second year teachers' experiences of support for their professional development. Cambridge Journal of Education, 42(2), 177-196.

\section{Acknowledgements}

We are grateful to the (then) Department for Children, Schools and Families, the General Teaching Council for England, and the Training and Development Agency for Schools, who co-funded the 'Becoming a Teacher' research, and to all members of the research team and project Steering Group for their valuable contributions to the study. We are also indebted to Angi Malderez, Mary Bailey, Tim Simkins and John Coldron (and to the anonymous reviewers and editor of the Cambridge Journal of Education) for their insightful comments on earlier versions of this article.

\section{References}

Abell, S.K., Dillon, D.R., Hopkins, C.J., McInerney, W.D. \& O’Brien, D.G. (1995).

"Somebody to count on": Mentor/intern relationships in a beginning teacher internship program. Teaching and Teacher Education, 11 (2), 173-188.

Ball, S. (2003). The teacher's soul and the terrors of performativity. Journal of Education Policy, 18, 215-228.

Barton, A. (2004). The Retention of Teachers of Priority Subjects during their First Three years in Service. London: Teacher Training Agency.

Bleicher, J. (1980). Contemporary Hermeneutics. London: Routledge.

Braun, V. \& Clarke, V. (2006). Using thematic analysis in psychology. Qualitative Research in Psychology, 3, 77-101.

Bullough, R.V., Jr. (2009). Seeking eudaimonia: The emotions in learning to teach and to mentor. In P. Schutz \& M. Zembylas (Eds.), Teacher emotion research: The impact on teachers' lives (33-53). New York: Springer.

Burn, K., Mutton, T. \& Hagger, H. (2010). Strengthening and sustaining professional learning in the second year of teaching. Oxford Review of Education, 36, 639-659. 
Hobson, A.J. \& Ashby, P. (2012) Reality aftershock and how to avert it: second year teachers' experiences of support for their professional development. Cambridge Journal of Education, 42(2), 177-196.

Corcoran, E. (1981) Transition Shock: The beginning teacher's paradox. Journal of Teacher Education, 32, 19-23.

Cordingley, P., Bell, M., Evans, D. \& Firth, A. (2005). The impact of collaborative continuing professional development (CPD) on classroom teaching and learning. Review: What do teacher impact data tell us about collaborative CPD? Retrieved from Research Evidence in Education Library, Institute of Education, University of London:

http://eppi.ioe.ac.uk/cms/Default.aspx?tabid=139

Department for Children, Schools \& Families (2008). School Teachers' Pay and Conditions Document. London: The Stationary Office.

DENI (2010). The Teacher Education Partnership Handbook (August 2010 Edition).

Retrieved from Department of Education Northern Ireland website:

http://www.deni.gov.uk/teacher_education_partnership_handbook_august_2010_.pdf

Eraut, M. (2007). Learning from other people in the workplace. Oxford Review of Education, $33,403-422$.

Field, A. (2000). Discovering statistics using SPPS for Windows (1st Edition). London: Sage.

Fenwick, A. \& Weir, D. (2010). The impact of disrupted and disjointed early professional development on beginning teachers. Teacher Development, 14, 501-517.

Gaede, O. (1978). Reality shock: a problem among first year teachers. The Clearing House, $51,405-409$.

Goddard, R., O’Brien, P. \& Goddard, M. (2006). Work environment predictors of beginning teacher burnout. British Educational Research Journal, 32, 857-874.

Gold, Y. (1996). Beginner Teacher Support: Attrition, mentoring and induction. In J. Sikula, T.J. Buttery \& E. Guyton (Eds), Handbook of Research on Teacher Education (548-594).

New York: Macmillan. 
Hobson, A.J. \& Ashby, P. (2012) Reality aftershock and how to avert it: second year teachers' experiences of support for their professional development. Cambridge Journal of Education, 42(2), 177-196.

Hagger, H. \& McIntyre, D. (2006). Learning teaching from teachers: Realising the potential of school-based teacher education. Maidenhead: Open University Press.

Hagger, H., Mutton, T. \& Burn, K. (2011). Surprising but not shocking: The reality of the first year of teaching, Cambridge Journal of Education, 41, 387-405.

Hammersley, M. (1996). The relationship between qualitative and quantitative research: paradigm loyalty versus methodological eclecticism, in J.T.E. Richardson (Ed.), Handbook of Qualitative Research Methods for Psychology and the Social Sciences. Leicester: British Psychological Society.

Hobson, A.J., (2009). On being bottom of the pecking order: beginner teachers' perceptions and experiences of support. Teacher Development, 13, 299-320.

Hobson, A.J., Malderez, A., Tracey, L., Homer, M.S., Ashby, P., Mitchell, N., McIntyre, J., Cooper, D., Roper, T., Chambers, G.N. \& Tomlinson, P.D. (2009). Becoming a Teacher: Teachers' experiences of initial teacher training, Induction and early professional development (Research Report No. DCSF-RR115). Retrieved from DES website: http://www.education.gov.uk/publications/eOrderingDownload/DCSF-RR115.pdf

Hobson, A.J., Malderez, A., Tracey, L., Homer, M., Mitchell, N., Biddulph, M., Giannakaki, M.S., Rose, A., Pell, R.G., Chambers, G.N., Roper, T. \& Tomlinson, P.D. (2007). Newly Qualified Teachers' experiences of their first year of teaching: Findings from Phase III of the Becoming a Teacher project (Research Report No. DCSF-RR08). Retrieved from DES website: http://www.education.gov.uk/publications/eOrderingDownload/DCSF-RR008.pdf

Hobson, A.J., McIntyre, J., Ashby, P., Hayward, V., Stevens, A. \& Malderez, A. (2012). The nature, impact and potential of external mentoring for teachers of physics and other subjects in England: Final report of the Modes of Mentoring \& Coaching (MoMaC) project to the Gatsby Charitable Foundation. Sheffield Hallam University. 
Hobson, A.J. \& Ashby, P. (2012) Reality aftershock and how to avert it: second year teachers' experiences of support for their professional development. Cambridge Journal of Education, 42(2), 177-196.

Holland, M., Hudson, T., Cripps, C., Barley, R. \& Wolstenholme, C. (2010). Evaluation of the Mentoring Extension to SASP Pilots: Final Report at End of Second Year. Centre for Education and Inclusion Research, Sheffield Hallam University.

Homer, M. Malderez, A., Hobson, A.J. \& Tracey, L. (2008). 'It's been a rollercoaster ride.' Beginning teachers' experiences of continuity and change from trainee to newly qualified teacher in England: Some findings from the Becoming a Teacher project. Paper presented at the Annual Conference of the British Educational Research Association, Edinburgh, September 2008.

Hoy, A. W. \& Spero, R. (2005). Changes in teacher efficacy during the early years of teaching: A comparison of four measures. Teaching and Teacher Education, 21, 343-356.

Huberman, M. (1989). The professional life cycle of teachers. Teachers' College Record, 91, $31-57$.

Johnson, S.M. (2004). Finders and Keepers: Helping New Teachers Survive and Thrive in Our Schools. San Francisco: Wiley.

Kwakman, K. (2003). Factors affecting teachers' participation in professional learning activities. Teaching and Teacher Education, 19, 149-70.

Luft, J. (2007). Minding the gap: Needed research on beginning/newly qualified science teachers. Journal of Research in Science Teaching, 44, 532-537.

Lumby, J. (2009). Performativity and identity: mechanisms of exclusion, Journal of Education Policy, 24:3, 353-369.

Mahony, P., Menter, I. \& Hextall, I. (2004). The emotional impact of performance-related pay on teachers in England, British Educational Research Journal, 30:3, 435-456. 
Hobson, A.J. \& Ashby, P. (2012) Reality aftershock and how to avert it: second year teachers' experiences of support for their professional development. Cambridge Journal of Education, 42(2), 177-196.

McIntyre, J., Hobson, A.J. \& Mitchell, N. (2009). Continuity, support, togetherness and trust: Findings from an evaluation of a university-administered early professional development programme for teachers in England. Professional Development in Education, 35, 357-379.

McKenzie, P. \& Santiago, P. (2005). Teachers Matter: Attracting, Developing and Retaining Effective Teachers. Paris: OECD Publishing.

Meirink, J.A., Imants, J., Meijer, P.C. \& Verloop, N. (2010). Teacher learning and collaboration in innovative teams. Cambridge Journal of Education, 40, 161-181.

Moor, H., Halsey, K., Jones, M., Martin, K., Stott, A., Brown, C. \& Harland, J. (2005). Professional Development for Teachers Early in their Careers: An Evaluation of the Early Professional Development Pilot Scheme (Research Report RR613). Retrieved from DFE website: http://www.education.gov.uk/publications/RSG/publicationDetail/Page1/RR613

Moor, H., Jones, M., Johnson, F., Martin, K., Cowell, E. and Bojke, C. (2006). Mathematics and Science in Secondary Schools: the Deployment of Teachers and Support Staff to Deliver the Curriculum (Research Report 708). Retrieved from DFE website: http://www.education.gov.uk/publications/eOrderingDownload/RR708.pdf

New Zealand Teachers Council (2011) Induction and Mentoring Programmes for Provisionally Registered Teachers (PRTs). Retrieved from New Zealand Teachers Council website: http://www.teacherscouncil.govt.nz/prt/

Schutz, A. (1967). The Phenomenology of the Social World. Evanston, IL: Northwestern University Press.

Shepherd, C. (2008). Towards physics: training programmes for non-specialists. School Science Review, 89, 1-5.

Shulman, L. S. (1986). Those who understand: Knowledge growth in teaching. Educational Researcher, 15, 4-14. 
Hobson, A.J. \& Ashby, P. (2012) Reality aftershock and how to avert it: second year teachers' experiences of support for their professional development. Cambridge Journal of Education, 42(2), 177-196.

Smith, T. \& Ingersoll, R. (2004). What are the effects of induction and mentoring on beginning teacher turnover? American Educational Research Journal, 41, 681-714.

Soares, A., Lock, R. \& Foster, J. (2008). Induction: the experiences of newly qualified science teachers, Journal of Education for Teaching, 34:3, 191-2.

Stokking, K., Leenders, F. De Jong, J., \& Van Tartwijk, J. (2003). From Student to Teacher: reducing practice shock and early dropout in the teaching profession. European Journal of Teacher Education, 26, 329-350.

Teaching \& Higher Education Act (1998). Office of Public Sector Information (OPSI). Retrieved from: http://www.opsi.gov.uk/acts/acts1998/ukpga_19980030_en_1.

Totterdell, M., Heilbronn, R., Bubb, S. \& Jones, C. (2002). Evaluation of the effectiveness of the Statutory Arrangements for the Induction of Newly Qualified Teachers (Research Report 338). Retrieved from DES website:

http://www.education.gov.uk/publications/eOrderingDownload/RR338.pdf

Tracey L., Homer, M., Mitchell, N., Malderez, A., Hobson, A.J., Ashby, P. \& Pell., G. (2008). Teachers' Experiences of their Second Year in Post: Findings from Phase IV of the Becoming a Teacher project. Nottingham: Department for Children, Schools and Families (DCSF).

Veenman, S.A.M. (1984). Perceived problems of beginning teachers. Review of Educational Research, 54, 143-178.

von Glaserfeld, E. (1996). Introduction: Aspects of Constructivism. In C.T. Fosnot (Ed), Constructivism: Theory, Perspectives and Practice (3-7). New York: Teachers College Press.

Wideen, M., Mayer-Smith, J. \& Moon, B. (1998). A Critical Analysis of the Research on Learning to Teach: Making the Case for an Ecological Perspective on Inquiry. Review of Educational Research, 68, 130-178. 
Hobson, A.J. \& Ashby, P. (2012) Reality aftershock and how to avert it: second year teachers' experiences of support for their professional development. Cambridge Journal of Education, 42(2), 177-196.

Williams, A. \& Prestage, S. (2002). The induction tutor: mentor, manager or both? Mentoring and Tutoring: Partnership in Learning, 10, 35-45.

Wilson, V., Hall, J., Davidson, J. \& Lewin, J. (2006). Developing teachers: A review of early professional learning. Glasgow: Glasgow University, SCRE Centre.

\section{Notes}

${ }^{1}$ Despite a number of policy changes relating to NQT induction since this time, most notably affecting changes to the national Standards against which NQTs are assessed, these two key features of support provision have remained in place since 1998.

${ }^{2}$ The sampling strategy underlying the initial questionnaire survey, carried out at the beginning of student teachers' final or only year of ITP, was informed by the twin aims of: (1) generating a representative sample of student teachers in England for each of the main ITP routes (Bachelor of Arts/Science with Qualified Teacher Status, Bachelor of Education, Postgraduate Certificate in Education [PGCE], Flexible PGCE, School-Centred Initial Teacher Training [SCITT], and Graduate and Registered Teacher Programmes [GRTP]); and (2) ensuring that a sufficient number of student teachers were recruited from among the routes with the fewest places, in order to enable viable statistical analysis by route up to the end of the project in 2009 (allowing for inevitable attrition both from teaching and the longitudinal survey over a 5 year period). The initial questionnaire was completed by 4790 student teachers, of whom 1973 participants completed the fourth survey at the end of their second year in post, the main focus of this article. Further details of the sampling strategy and attrition from the research are provided in Hobson et al. (2009).

${ }^{3}$ Initial face-to-face interviews were conducted with 85 survey respondents who indicated a willingness to participate in the research further. Of these, 73 were interviewed at the end of their first year in post and 64 at the end of their second.

${ }^{4}$ Interviewees still participating in the research during their first year of teaching were invited to respond electronically to emails seeking to elicit their views and experiences: 46 NQTs responded to at least one email during that year, while 45 participants did so during their second year in post.

${ }^{5}$ We use inverted commas here to acknowledge that the distinction between quantitative and qualitative methods and data is somewhat simplistic and exaggerated (Hammersley, 1996).

${ }^{6}$ Further information regarding the selection of these participants is provided in the final part of the Findings section.

${ }^{7}$ Our survey data suggest that approximately 78 per cent of respondents successfully completed their NQT induction programmes by the end of their first year in post, and a further 19 per cent during their second year. Some participants had been judged not to have met the Standards by the end of their first year in post, while some had not had access to an induction programme (e.g. because they had been employed on short term supply contracts) and others had not yet had time to complete their induction (e.g. because they had worked part-time).

${ }^{8}$ There are few indications in the data of which of these kinds of support participants most missed: those RQTs who felt unsupported rarely distinguished between the two kinds and tended to bemoan a lack of support per se.

${ }^{9}$ As Table 3 indicates, only respondents employed on permanent or fixed term contracts were asked this question. It can be fairly safely assumed that few RQTs undertaking supply work will have had access to a mentor.

${ }^{10}$ There were some indications in our data that the second year experience of beginner teachers who completed their NQT induction in one year but not by the end of their first summer term (e.g. because for one reason or another they did not take up a teaching post in the autumn term following their completion of ITP) could be rather different from that of most RQTs. For example, refreshed by the summer break, these teachers could potentially take on the additional responsibilities of the new school year while still, for a term at least, enjoying the additional support entitlements of an NQT. 
Hobson, A.J. \& Ashby, P. (2012) Reality aftershock and how to avert it: second year teachers' experiences of support for their professional development. Cambridge Journal of Education, 42(2), 177-196.

${ }^{11}$ Since this (13 per cent) figure is based upon those remaining in the survey, and since it is likely that those who had left teaching were less likely to participate in the survey, it is possible that the real number was considerably higher.

${ }^{12}$ While the findings presented in this article relate to second year teachers, those presented elsewhere show that some teachers continue to have important support needs after this period (Hobson et al., 2009; Moor et al., 2005).

${ }^{13}$ Beginner teachers following the Northern Irish EPD programme are also able to access support from a Curriculum Advisory and Support Service (CASS) (DENI, 2010).

${ }^{14}$ The University of Cambridge EPD Programme was sponsored by the Gatsby Charitable Foundation, whose financial support enabled schools to provide supply teaching cover to allow NQTs/RQTs to attend Development Days during school time.

15 The regional mentoring associated with PEP and SASP pilot programmes was coordinated by the Institute of Physics and also funded by the Gatsby Charitable Foundation. 